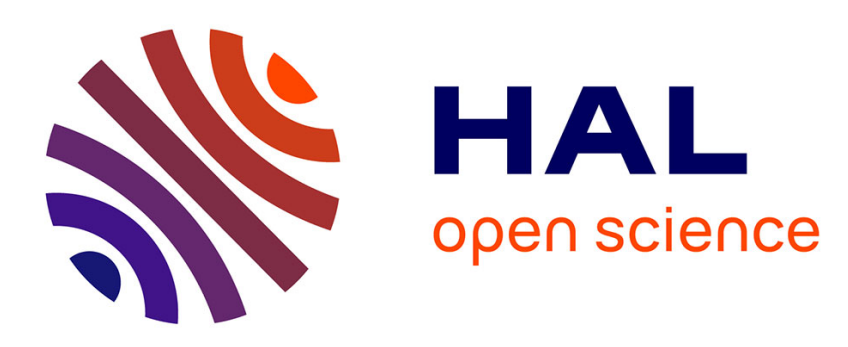

\title{
Dopant Diffusion in Si1-xGex Thin Films: Effect of Epitaxial Stress
}

\author{
A. Portavoce, I. Berbezier, A. Ronda, P. Gas, J S Christensen, A Yu \\ Kuznetsov, B. Svensson
}

\section{To cite this version:}

A. Portavoce, I. Berbezier, A. Ronda, P. Gas, J S Christensen, et al.. Dopant Diffusion in Si1xGex Thin Films: Effect of Epitaxial Stress. Defect and Diffusion Forum, 2006, 249, pp.135-142. 10.4028/www.scientific.net/DDF.249.135 . hal-02406700

\section{HAL Id: hal-02406700 https://hal-amu.archives-ouvertes.fr/hal-02406700}

Submitted on 12 Dec 2019

HAL is a multi-disciplinary open access archive for the deposit and dissemination of scientific research documents, whether they are published or not. The documents may come from teaching and research institutions in France or abroad, or from public or private research centers.
L'archive ouverte pluridisciplinaire HAL, est destinée au dépôt et à la diffusion de documents scientifiques de niveau recherche, publiés ou non, émanant des établissements d'enseignement et de recherche français ou étrangers, des laboratoires publics ou privés. 


\title{
Dopant Diffusion in $\mathrm{Si}_{1-\mathrm{x}} \mathbf{G e}_{\mathrm{x}}$ Thin Films: Effect of Epitaxial Stress
}

\author{
A. Portavoce ${ }^{1, a}$, I. Berbezier ${ }^{1, b}$, A. Ronda $a^{1, c}$, P.Gas ${ }^{1, d}$, J.S. Christensen ${ }^{2, e}$, \\ A. Yu. Kuznetsov ${ }^{2, f}$, B.G. Svensson ${ }^{2, g}$ \\ ${ }^{1}$ L2MP-CNRS, Université Paul Cézanne, Case 142, 13397 Marseille Cedex 20, France \\ ${ }^{2}$ Fysisk Institutt, PO Box 1048 Blindern, NO-0316 Oslo, Norway \\ aalain.portavoce@I2mp.fr, ${ }^{b}$ isabelle.berbezier@l2mp.fr, ${ }^{c}$ antoine.ronda@I2mp.fr, \\ j.s.christensen@fys.uio.no, fa.y.kuznetsov@fys.uio.no, 9b.g.svesson@fys.uio.no
}

Keywords: Diffusion, B, Sb, SiGe, Biaxial stress

\begin{abstract}
We have investigated the lattice diffusion of $\mathrm{B}$ and $\mathrm{Sb}$ by means of molecular beam epitaxy in $\mathrm{Si}_{1-\mathrm{x}} \mathrm{Ge}_{\mathrm{x}}(x<0.2)$ layers grown on $\mathrm{Si}(001)$ substrate. Using $\mathrm{Si}_{1-\mathrm{x}} \mathrm{Ge}_{\mathrm{x}}$ relaxed buffers we were able to differentiate the chemical effect (change in the Ge composition) as opposite to the biaxial stress effect (due to the epitaxy on $\mathrm{Si}$ ) on dopant diffusion. B diffusion follows a behavior opposite to $\mathrm{Sb}$ diffusion versus Ge composition and biaxial stress. These results are explained in view of the difference of diffusion mechanism between B (interstitials) and Sb (vacancies). We also show that dopant diffusion follows contrasting behaviors under biaxial pressure and hydrostatic pressure, and that the activation volume of dopant diffusion is of opposite sign for biaxial pressure and for hydrostatic pressure. This is explained using a formalism based on the extra work done by the system for diffusion under pressure, concluding that for biaxial stress the activation volume depends mainly on the relaxation volume linked to the defect formation.
\end{abstract}

\section{Introduction}

Biaxial stress is frequently met in microelectronic structures, which are composed of a stack of different semiconductor layers with different composition and strain states [1]. The influence of hydrostatic pressure on atom diffusion had been commonly employed to evidence diffusion mechanisms [2], but experimentally few tests have been done exploring the relationship between diffusion mechanism and biaxial stress $[3,4,5,6]$. The stress resulting from the epitaxy being biaxial, the molecular beam epitaxy (MBE) deposition technique offers the possibility to make $\mathrm{Si}_{1-\mathrm{x}} \mathrm{Ge}_{\mathrm{x}}$ layers under different biaxial stress states [7]. In this paper we choose to study the influence of biaxial pressure on the diffusion of $\mathrm{B}$ and $\mathrm{Sb}$ that use different diffusion mechanisms in $\mathrm{Si}_{1-\mathrm{x}} \mathrm{Ge}_{\mathrm{x}}(\mathrm{x}$ $<0.2$ ). Indeed, our aim is to compare the influence of biaxial and hydrostatic pressure on interstitial mediated diffusion (B) and vacancy mediated diffusion (Sb). Furthermore, we aim to give an interpretation linking the effect of the two types of pressure to these diffusion mechanisms (see Aziz $[8,9])$.

\section{Experimental}

The $\mathrm{Si}_{1-\mathrm{x}} \mathrm{Ge}_{\mathrm{x}}$ layers were grown in a Riber molecular beam epitaxy (MBE) system with a base pressure typically $<10^{-11}$ Torr. Silicon was evaporated using an electron beam evaporator. Ge, B and $\mathrm{Sb}$ were evaporated from effusion cells. Three types of $\mathrm{Si}_{1-\mathrm{x}} \mathrm{Ge}_{\mathrm{x}}$ structures were produced: (i) relaxed layers $(x=0,0.09$ and 0.18$)$, (ii) compressively strained layers $(x=0.09$ and 0.18$)$ and (iii) layers under tensile strain $(x=0.09)$. Each sample is composed of a dopant diffusion source $(0.1$ monolayer of $\mathrm{B}$ or 0.5 monolayer of $\mathrm{Sb}$ ) deposited between two $50 \mathrm{~nm}$ thick $\mathrm{Si}_{1-\mathrm{x}} \mathrm{Ge}_{\mathrm{x}}$ layers grown at $550^{\circ} \mathrm{C}$. For the compressively strained samples, these layers were grown directly on $\mathrm{Si}(100)$ and were covered with $20 \mathrm{~nm}$ of $\mathrm{Si}$ at low temperature $\left(T<200^{\circ} \mathrm{C}\right)$. The relaxed structures were grown on the same composition $\mathrm{Si}_{1-\mathrm{x}} \mathrm{Ge}_{\mathrm{x}}$ relaxed buffer layer deposited on the $\mathrm{Si}(001)$ substrate. The 
structures under tensile strain were grown for epitaxy on a relaxed $\mathrm{Si}_{0.81} \mathrm{Ge}_{0.19}$ buffer. Fig. 1 is a schematic presentation of these different structures. The concentration of dislocations in the relaxed $\mathrm{Si}_{1-\mathrm{x}} \mathrm{Ge}_{\mathrm{x}}$ buffers was measured by means of atomic force microscopy and transmission electron microscopy. It was found to be lower than $10^{5} \mathrm{~cm}^{-2}$. X-ray diffraction measurements confirmed that the level of relaxation in these buffers was larger than $95 \%$.
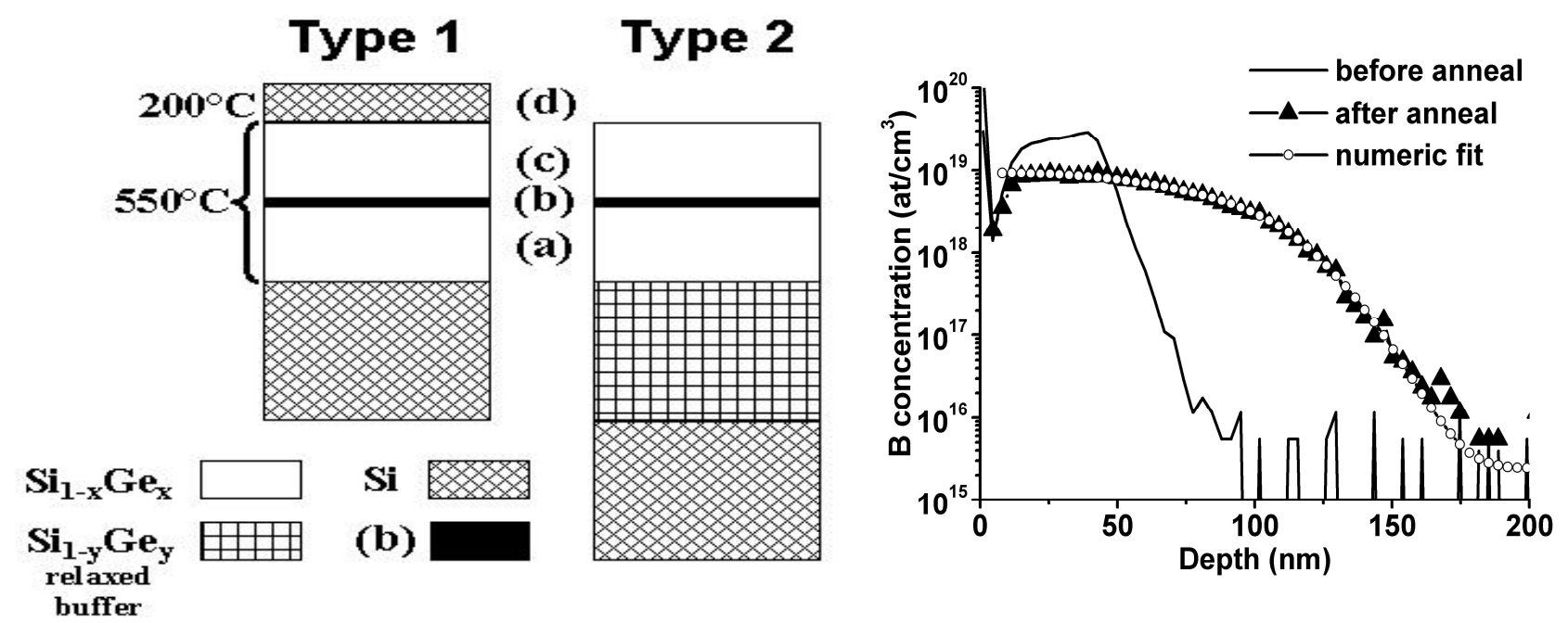

Fig. 1. Schematic presentation of the structures grown Fig. 2. B concentration profiles measured by $\mathrm{MBE}$ on $\mathrm{Si}(001)$. For the type 1 structure, the by SIMS in a relaxed $\mathrm{Si}_{1-\mathrm{x}} \mathrm{Ge}_{\mathrm{x}}$ layer $(\mathrm{x}=$ $\mathrm{Si}_{1-\mathrm{x}} \mathrm{Ge}_{\mathrm{x}}$ layer is under biaxial compressive stress. For 0.09 ) before (full line) and after (triangles) the type 2 structure, the $\mathrm{Si}_{1-\mathrm{x}} \mathrm{Ge}_{\mathrm{x}}$ layer is relaxed if $\mathrm{y}=$ annealing at $900{ }^{\circ} \mathrm{C}$ for $1 \mathrm{~h}$, and the $\mathrm{x}$, and under biaxial tensile stress if $\mathrm{y}>\mathrm{x}$. The layer simulated profile (open circles) allowing (b) located in the middle of the $\mathrm{Si}_{1-\mathrm{x}} \mathrm{Ge}_{\mathrm{x}}$ layer is the the measurement of the corresponding dopant diffusion source $(0.1$ monolayer of $\mathrm{B}$ or 0.5 coefficient of diffusion. monolayer of $\mathrm{Sb}$ ).

The dopant concentration versus depth of the samples was measured by Secondary Ion Mass Spectroscopy (SIMS) using a Cameca IMS4F operated at $8 \mathrm{Kev}$ with $\mathrm{O}_{2}{ }^{+}$primary ions. The Ge composition of the layers was measured by Rutherford Backscattering Spectrometry (RBS).

Each sample was cleaved in several pieces, then one of them was kept as a reference and the others were annealed. The $\mathrm{B}$ doped samples were annealed in the same furnace under inert $\mathrm{N}_{2}$ atmosphere at $900{ }^{\circ} \mathrm{C}$ while the $\mathrm{Sb}$ doped samples were annealed in the same vacuum furnace ( $\mathrm{P}$ $\sim 10^{-6}$ Torr) at $800^{\circ} \mathrm{C}$. In order to measure the diffusivity, we performed a numeric resolution of the diffusion equation using the SIMS profile in the reference piece as departure distribution, and using the SIMS profile in the annealed pieces as final distribution. For example, Fig. 2 shows the B concentration profiles measured in the unstressed $\mathrm{Si}_{0.91} \mathrm{Ge}_{0.09}$ sample before and after annealing at $900{ }^{\circ} \mathrm{C}$, and the numeric fit that allowed extraction of the diffusion coefficient in this layer.

\section{Results}

Fig. 3 shows the variations of the $\mathrm{B}$ diffusion coefficient versus the Ge composition for unstressed and compressively stressed $\mathrm{Si}_{1-\mathrm{x}} \mathrm{Ge}_{\mathrm{x}}$ layers. For both types of film the B diffusion decreases when the Ge concentration increases. One can notice that for constant Ge composition, a compressive biaxial stress decreases the diffusion coefficient of B. Fig. 4 presents the variations of the $\mathrm{Sb}$ diffusion coefficient versus the Ge composition for unstressed and compressively stressed $\mathrm{Si}_{1-\mathrm{x}} \mathrm{Ge}_{\mathrm{x}}$ layers. For both types of film, contrasting with $\mathrm{B}$, the $\mathrm{Sb}$ diffusion increases with the $\mathrm{Ge}$ concentration, and for constant Ge composition the diffusion coefficient of $\mathrm{Sb}$ increases under compressive biaxial stress. 

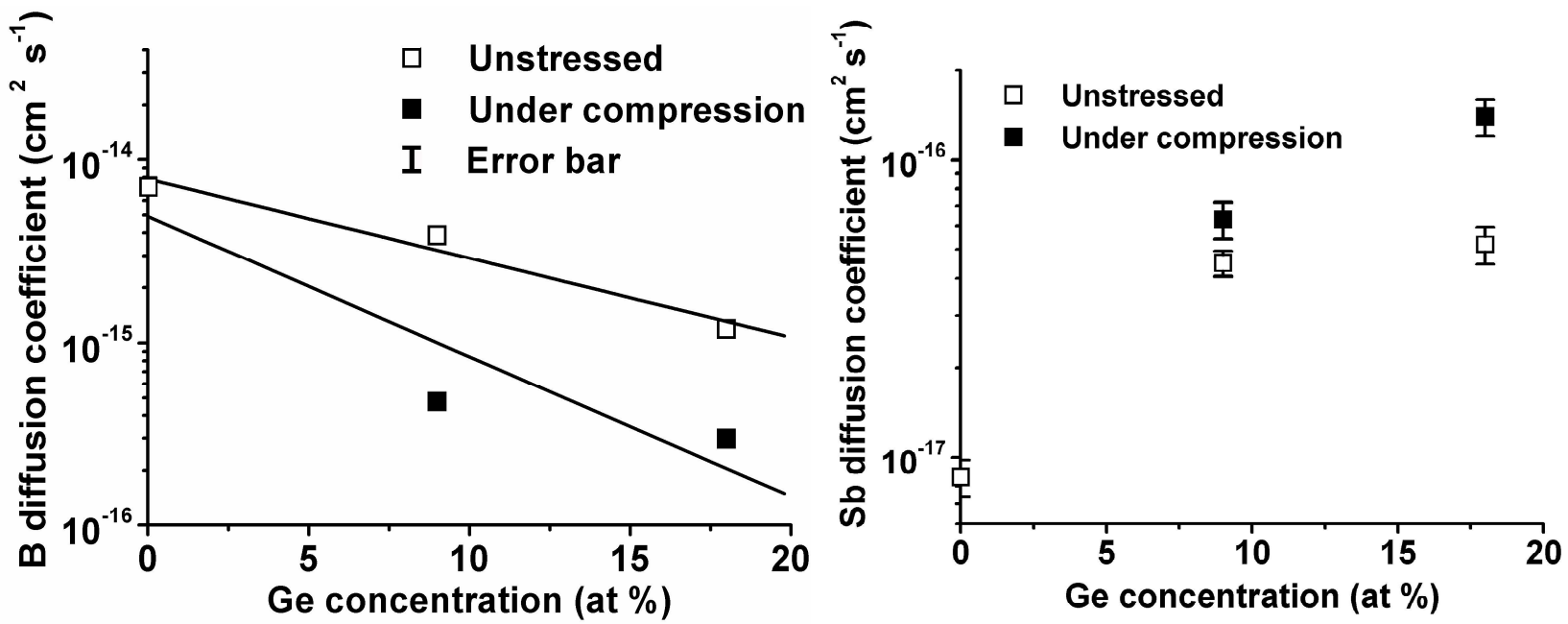

Fig. 3. Variation of the $\mathrm{B}$ diffusion coefficient Fig. 4. Variation of the Sb diffusion coefficient measured at $900{ }^{\circ} \mathrm{C}$ versus the Ge concentration in measured at $800{ }^{\circ} \mathrm{C}$ versus the Ge concentration unstressed (empty square) and compressively stressed in unstressed (empty square) and compressively (solid square) $\mathrm{Si}_{1-\mathrm{x}} \mathrm{Ge}_{\mathrm{x}}$ layers. stressed (solid square) $\mathrm{Si}_{1-\mathrm{x}} \mathrm{Ge}_{\mathrm{x}}$ layers.

Figs. 5 and 6 present the variation of the diffusion coefficients of $\mathrm{B}$ and $\mathrm{Sb}$, respectively, in $\mathrm{Si}_{0.91} \mathrm{Ge}_{0.09}$ versus the biaxial pressure $\left(\mathrm{P}^{\mathrm{b}}\right)$ that we defined as [10]:

$$
P^{b}=2 \mu \frac{v+1}{v-1} \frac{a_{f i l m}-a_{s u b}}{a_{s u b}} .
$$

$\mathrm{a}_{\text {film }}, \mu$ and $v$, are respectively, the unconstrained lattice parameter, the shear modulus and the Poisson's ratio of the film, and $\mathrm{a}_{\text {sub }}$ is the lattice parameter of the substrate. This equation gives positive pressures for biaxial compression and negative pressures for biaxial tension. The diffusion coefficients of $\mathrm{B}$ and $\mathrm{Sb}$ follow contrasting behavior versus the biaxial pressure: the diffusion of $\mathrm{B}$ decreases under biaxial pressure while $\mathrm{Sb}$ increases and vise versa under biaxial tension.

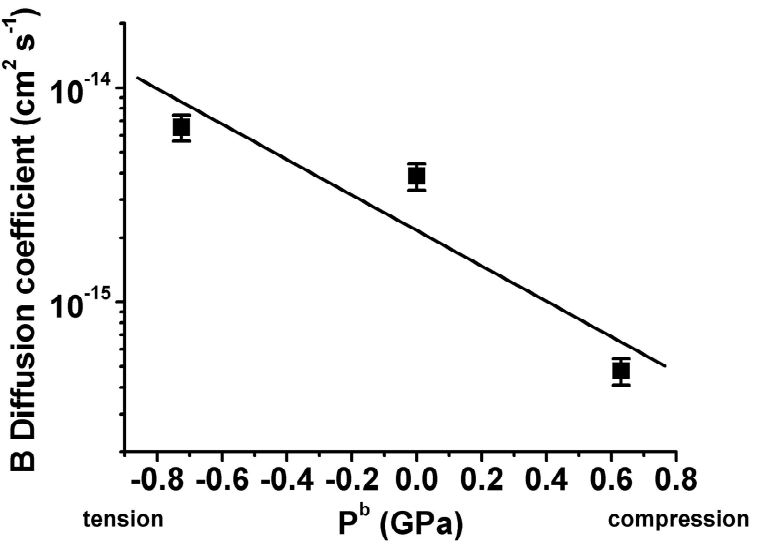

Fig. 5. Variation of the $\mathrm{B}$ diffusion coefficient at $900{ }^{\circ} \mathrm{C}$ with the biaxial pressure $\left(\mathrm{P}^{\mathrm{b}}\right)$ in $\mathrm{Si}_{0.91} \mathrm{Ge}_{0.09}$.

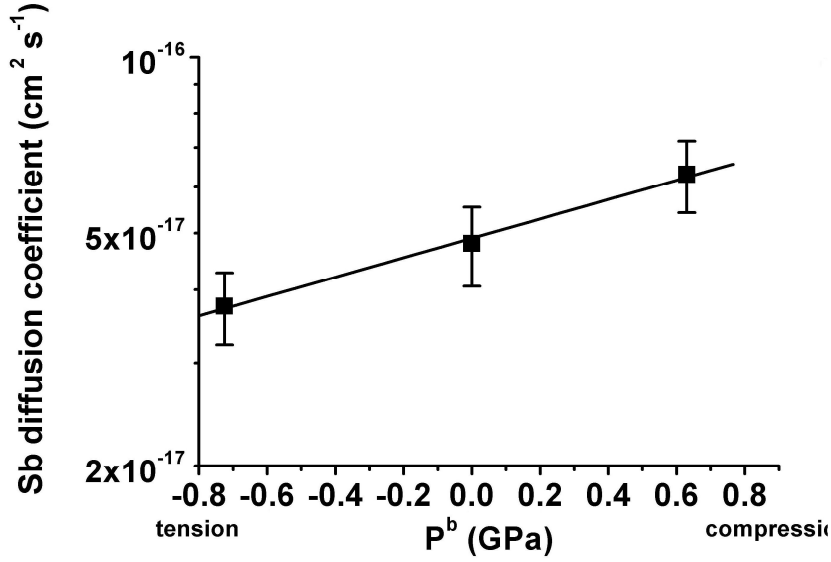

Fig. 6. Variation of the $\mathrm{Sb}$ diffusion coefficient at $800{ }^{\circ} \mathrm{C}$ with the biaxial pressure $\left(\mathrm{P}^{\mathrm{b}}\right)$ in $\mathrm{Si}_{0.91} \mathrm{Ge}_{0.09}$.

Assuming that the diffusion is mediated by only one major mechanism and knowing the variation of the diffusion coefficient versus pressure, the activation volume of diffusion $(\Delta V)$ can be obtained from the following equation $[2,11]$ : 


$$
\Delta V=-k T \frac{d \ln D}{d P}
$$

with $\mathrm{k}$ the Boltzmann's constant, $\mathrm{T}$ the temperature and $\mathrm{D}$ the diffusion coefficient. $\Delta \mathrm{V}$ is defined as the sum of two volume variations: a volume variation $\left(\Delta V^{f}\right)$ due to the formation of the defect linked to the diffusion and a volume variation $\left(\Delta V^{\mathrm{m}}\right)$ due to the migration of the defect during the diffusion.

$$
\Delta V=\Delta V^{f}+\Delta V^{m}
$$

The activation volume under biaxial pressure $\left(\Delta V^{b}\right)$ had been deduced from the fit of the data presented in Figs. 5 and 6. In the case of B diffusion, $\Delta V^{b}$ has been found to be positive and equal to $1.53 \Omega\left(\Omega\right.$ being the atomic volume). In the case of $\mathrm{Sb}, \Delta V^{\mathrm{b}}$ has been found to be negative and equal to $-2.28 \Omega$.

\section{Discussion}

The variations of the lattice diffusion coefficients of $\mathrm{B}$ and $\mathrm{Sb}$ versus the Ge composition can be understood considering that $\mathrm{B}$ diffusion is interstitial mediated and that $\mathrm{Sb}$ diffusion is vacancy mediated [12]. The melting point of $\mathrm{Ge}\left(938.3^{\circ} \mathrm{C}\right)$ is lower than the melting point of $\mathrm{Si}\left(1414^{\circ} \mathrm{C}\right)$ leading to an increase of the vacancy concentration and a decrease of the interstitial concentration in $\mathrm{Si}_{1-\mathrm{x}} \mathrm{Ge}_{\mathrm{x}}$ when $\mathrm{x}$ increases [13].

Zhao et al. [14,15] have shown that in $\mathrm{Si}$, the B diffusion increases while the $\mathrm{Sb}$ diffusion decreases under hydrostatic pressure. This has been also explained considering the variation of point defect concentration versus pressure. Indeed, under hydrostatic pressure the concentration of interstitials increases and the concentration of vacancies decreases [16]. They have shown that under hydrostatic pressure the activation volume is negative for $\mathrm{B}$ diffusion $\left(\Delta V^{\mathrm{H}}=-0.17 \Omega\right.$ at $\left.810^{\circ} \mathrm{C}\right)$ and positive for $\mathrm{Sb}$ diffusion $\left(\Delta V^{\mathrm{H}}=0.07 \Omega\right.$ at $\left.860^{\circ} \mathrm{C}\right)$. One can notice that under biaxial pressure the diffusion of $\mathrm{B}$ and $\mathrm{Sb}$ still follow different behaviors, which can be due to their difference of diffusion mechanism, but the diffusion of $\mathrm{B}$ and $\mathrm{Sb}$ exhibit variations opposite to their variations under hydrostatic pressure. A preliminary explanation can be given considering the creep theory. In the case of a biaxial compression, one can expect a dilatation of the film along the direction normal to the free surface (surface normal to the direction of diffusion where no pressure is applied) in order to relax the stress. This dilatation can be assisted by the formation of additional vacancies in the crystal allowing better stress relaxation. Thus, contrasting with hydrostatic pressure, a biaxial pressure should promote an increase of the vacancy concentration and a decrease of the interstitial concentration, explaining the opposite behavior of dopant diffusion versus hydrostatic and biaxial pressure. The diffusion coefficient can be written as:

$$
\begin{aligned}
& D=A \exp \left[\frac{\Delta S}{k}\right] \exp \left[\frac{-\Delta H}{k T}\right] \\
& D=D_{0} \exp \left[\frac{-E}{k T}\right] \quad \text { with } D_{0}=A \exp \left[\frac{\Delta S}{k}\right] \text { and } \Delta H=E .
\end{aligned}
$$

$\Delta S, \Delta H$, and $E$ are respectively the entropy variation, the enthalpy variation and the activation energy of diffusion. $D_{0}$ is called the pre-exponential factor of the diffusion coefficient. Under pressure, one can consider that the system has to provide an extra work $(W)$ for atom diffusion. The expression of the coefficient of diffusion becomes: 


$$
D=D_{0} \exp \left[\frac{-(E+W)}{k T}\right]=D_{\text {relax }} \exp \left[\frac{-W}{k T}\right]
$$

with $\mathrm{D}_{\text {relax }}$ the diffusion coefficient without pressure $(P=0)$. W is the sum of the works done against the pressure for the formation $\left(W^{\mathrm{f}}\right)$ and the migration $\left(W^{\mathrm{m}}\right)$ of the defect related to the diffusion mechanism:

$$
\begin{aligned}
W & =\sum_{i=1}^{3} W_{i}^{f}+\sum_{i=1}^{3} W_{i}^{m} \text { with } W_{i}=+p_{i} \Delta V_{i} \\
W & =\sum_{i=1}^{3} p_{i}\left(\Delta V_{i}^{f}+\Delta V_{i}^{m}\right) .
\end{aligned}
$$

The index i corresponds to the three directions of space. Eq. 8 gives for hydrostatic pressure:

$$
W^{H}=p\left( \pm \Omega+\Delta V^{r}+\Delta V^{m}\right) \text { with } p_{i}=p \quad \text { and } \quad \Delta V^{f}= \pm \Omega+\Delta V^{r}
$$

$\Omega$ is the atomic volume with (+) for a vacancy and (-) for an interstitial, and $\Delta V^{\mathrm{r}}$ is the relaxation volume of the point defect. Usually $\Delta V^{\mathrm{T}}$ is expected to be smaller than $\Omega$, positive for an interstitial and negative for a vacancy. Assuming that the defect formation is localized at the free surface $[8,9]$, for biaxial pressure Eq. 8 gives:

$$
W^{b}=2 p\left(\Delta V_{\perp}^{r}+\Delta V_{\perp}^{m}\right)
$$

$V_{\mathrm{j}}^{\mathrm{r}}$ is the relaxation volume and $V_{\mathrm{j}}^{\mathrm{m}}$ is the migration volume of the defect in the direction $j$ (normal or parallel to the direction of diffusion). The defect's migration volume can be understood as the variation of the defect's relaxation volume during atom motion. If we assume that the defect has a constant volume during diffusion, which indicates that lattice distortions are in an elastic regime and that each direction in the lattice has a constant elasticity, then $\Delta V_{\perp}{ }^{\mathrm{m}}=0$ and $\Delta V_{/ /}^{\mathrm{m}}=0$ leading to $\Delta V^{\mathrm{m}}=0$. This assumption is equivalent to neglecting the migration part of the activation volume. With this approximation, we obtain for an interstitial mechanism:

$$
\begin{aligned}
& W^{H}=p\left(-\Omega+\left|\Delta V^{r}\right|\right) \leq 0 \quad \text { with } \quad \Delta V^{H}=\left(-\Omega+\left|\Delta V^{r}\right|\right) \leq 0 \\
& W^{b}=2 p\left|\Delta V_{\perp}^{r}\right| \geq 0 \quad \text { with } \quad \Delta V^{b}=2\left|\Delta V_{\perp}^{r}\right| \geq 0
\end{aligned}
$$

and for a vacancy mechanism:

$$
\begin{aligned}
& W^{H}=p\left(+\Omega-\left|\Delta V^{r}\right|\right) \geq 0 \quad \text { with } \quad \Delta V^{H}=\left(+\Omega-\left|\Delta V^{r}\right|\right) \geq 0, \\
& W^{b}=-2 p\left|\Delta V_{\perp}^{r}\right| \leq 0 \quad \text { with } \quad \Delta V^{b}=-2\left|\Delta V_{\perp}^{r}\right| \leq 0 .
\end{aligned}
$$

Considering the diffusion mechanism of $\mathrm{B}$ and $\mathrm{Sb}$ in $\mathrm{Si}_{1-\mathrm{x}} \mathrm{Ge}_{\mathrm{x}}(\mathrm{x} \leq 0.2)$, Eqs. 11 to 14 combined with Eq. 6 lead to the correct variation of the diffusion coefficient of $\mathrm{B}$ and $\mathrm{Sb}$ versus hydrostatic and biaxial pressure. We obtain the correct sign for the activation volumes of $\mathrm{B}$ and $\mathrm{Sb}$ versus the pressure type. This interpretation supposes that the activation volume under biaxial stress depends mainly on the relaxation volume of the point defect linked to the diffusion mechanism, assuming that the point defect formation is principally located at free surface. 


\section{Conclusion}

The $\mathrm{B}$ and $\mathrm{Sb}$ diffusion in $\mathrm{Si}_{1-\mathrm{x}} \mathrm{Ge}_{\mathrm{x}}$ layers $(0 \leq \mathrm{x}<0.2)$ grown by molecular beam epitaxy on $\mathrm{Si}(001)$ substrates have been investigated. The lattice diffusion coefficient of B decreases when the Ge concentration increases in relaxed layers (chemical or alloying effect), decreases under biaxial compressive stress, increases under biaxial tensile stress. Furthermore, the combined effects of chemistry and stress lead to the decrease of the $\mathrm{B}$ diffusivity in $\mathrm{Si}_{1-\mathrm{x}} \mathrm{Ge}_{\mathrm{x}}$ layers in epitaxy on $\mathrm{Si}$ substrates. The diffusion coefficient of $\mathrm{Sb}$ follows the opposite variations versus composition and stress, and the activation volumes of $\mathrm{B}$ and $\mathrm{Sb}$ under biaxial pressure have opposite sign. Observing that $\mathrm{B}$ and $\mathrm{Sb}$ follow contrasting behaviors under hydrostatic pressure, we show that the results can be explained using a formalism based on the extra-work made by the system for diffusion under pressure and considering the diffusion mechanisms of the dopants. This formalism supposes that the activation volume of diffusion under biaxial stress involves only the relaxation volume of the defect (we neglect the volume of migration), explaining the opposite behavior of dopant diffusion under hydrostatic and biaxial pressure.

\section{References}

[1] U. König, M. Zeuner, G. Hock, T. Hackbarth, M. Gluck, T. Ostermann and M. Saxarra: SolidState Electr. Vol. 43 (1999), p. 1383

[2] N.A. Stolwijk and H. Bracht: Landolt-Bornstein-Numerical Data and Functional Relationships in Science and Technology (edited by D. Beke, Springer-Verlag, Berlin 1998) Vol. III-33A, p. 2-1

[3] N.E.B Cowern, P.C. Zalm, P. van der Sluis, D.G. Gravesteijn, W.B. de Boer: Phys. Rev. Lett. Vol. 72 (1994), p. 2585

[4] P. Kuo, J.L. Hoyt and J.F. Gibbons: Appl. Phys. Lett. Vol. 66 (1995), p. 580

[5] A. Nylandsted Larsen and P. Kringhoj: Appl. Phys. Lett. Vol. 68 (1996), p. 2684

[6] N.R. Zangenberg, J. Fage-Pedersen, J. Lundsgaard Hansen and A. Nylandsted Larsen: J. Appl. Phys. Vol. 94 (2003), p. 3883

[7] P. Kringhoj, A. Nylandsted Larsen and S.Y. Shirayev: Phys. Rev. Lett. Vol. 76 (1996), p. 3372

[8] M.J. Aziz: Defects and Diffusion in Silicon Processing (edited by T. Diaz de la Rubia et al., Mater. Res. Soc. Symp. Proc. No. 469, Warrendale, Philadelphia 1997), p. 37

[9] M.J. Aziz: Appl. Phys. Lett. Vol. 70 (1997), p. 2810

[10] I. Markov: Crystal Growth for Beginners (World Scientific, Singapore1995)

[11] W. Frank, U. Gosele, H. Mehrer and A. Seeger: Diffusion in Crystalline Solids (Academic Press, New York 1984) p. 63

[12] Landolt-Börnstein: Diffusion in Semiconductors and Nonmetallic Solids (edited by D. L. Beke, Springer, Berlin 1998), Vol. 3

[13] J. Philibert: Atom Movements, Diffusion and Mass Transport in Solids (Editions de Physique, Les Ulis 1991)

[14] Y. Zhao, M.J. Aziz, H.-J. Gossmann, S. Mitha and D. Schiferl: Appl. Phys. Lett. Vol. 74 (1999), p. 31

[15] Y. Zhao, M.J. Aziz, H.-J. Gossmann, S. Mitha and D. Schiferl: Appl. Phys. Lett. Vol. 75 (1999), p. 941

[16] A. Antonelli and J. Bernholc: Phys. Rev. B Vol. 40 (1989), p. 10643 


\section{Discussion}

\section{J. Philibert:}

What would be the effect of biaxial stresses if you were measuring diffusivity in a direction that lies in this plane - and not perpendicular as in your experiment?

\section{A. Portavoce:}

We have measured the diffusivity of $\mathrm{B}$ and $\mathrm{Sb}$ in the same direction, perpendicular to the surface either when the $\mathrm{Si}(\mathrm{Ge})$ layer is under biaxial compression or under biaxial tension. We have shown their diffusivity follows an opposite behavior in this direction if the layer is under biaxial compression or biaxial tension. This variation of diffusion versus the biaxial stress have been interpreted considering the global variation of joint defect concentration in the layer. It is interesting to notice there if the $\mathrm{Si}(\mathrm{Ge})$ layer is under biaxial compression in the direction perpendicular to the direction of diffusion, the same layer is also under biaxial tension in the direction parallel to the direction of diffusion and vice versa. In consequence it would be very interesting to measure the diffusion of a dopant in the two directions parallel and perpendicular to the surface of the same $\mathrm{Si}(\mathrm{Ge})$ layer under biaxial stress. If the same diffusivity would be found, we could conclude that the diffusion variations under biaxial pressure is due to a global change of the point defect concentration in the layer. While if it is not the case, if the diffusivity is enhanced in one direction and reduced in the other one, we would have to consider the effect of the lattice strain (which is not homogeneous in these two directions) on the jump frequency.

\section{J. Philibert:}

Could it be possible to predict the effect of the concentration on the basis of the activation volume: the size effect of the solute generates an internal stress - a pressure positive or negative according to the sign of the size effect.

\section{A. Portavoce:}

To investigate the effect of the composition of the layers on dopant diffusion, we need to consider the variation of diffusion versus the Ge concentration in relaxed layers. As an example, Sb is a "bigger" atom than Si and Ge. The addition of Ge in Si leads to the increase of the lattice parameter of the matrix. This means that that the size effect of $\mathrm{Sb}$ atoms on the substitutional sites of the matrix should decrease when the Ge content of the layer increases. But we observe an increase of the $\mathrm{Sb}$ diffusivity with the $\mathrm{Ge}$ concentration. The increase of the $\mathrm{Sb}$ diffusivity in $\mathrm{Si}(\mathrm{Ge})$ layers under biaxial compression versus the Ge concentration had been interpreted as a combined effect of alloying and stress.

\section{Beke:}

How your model of explanation is related to the model of Aziz et al. for the effect of stress on the Sb diffusion?

\section{A. Portavoce:}

Our interpretation is based on the model presented by Aziz: First, we assume that the activation volume can be written as the sum of three components along the 3 directions of space. Second, following Aziz, we assume that under biaxial stress the defect formation takes place at the free surface, which leads to the vanishing of the atomic volume in the expression of the extra-work under biaxial pressure. 


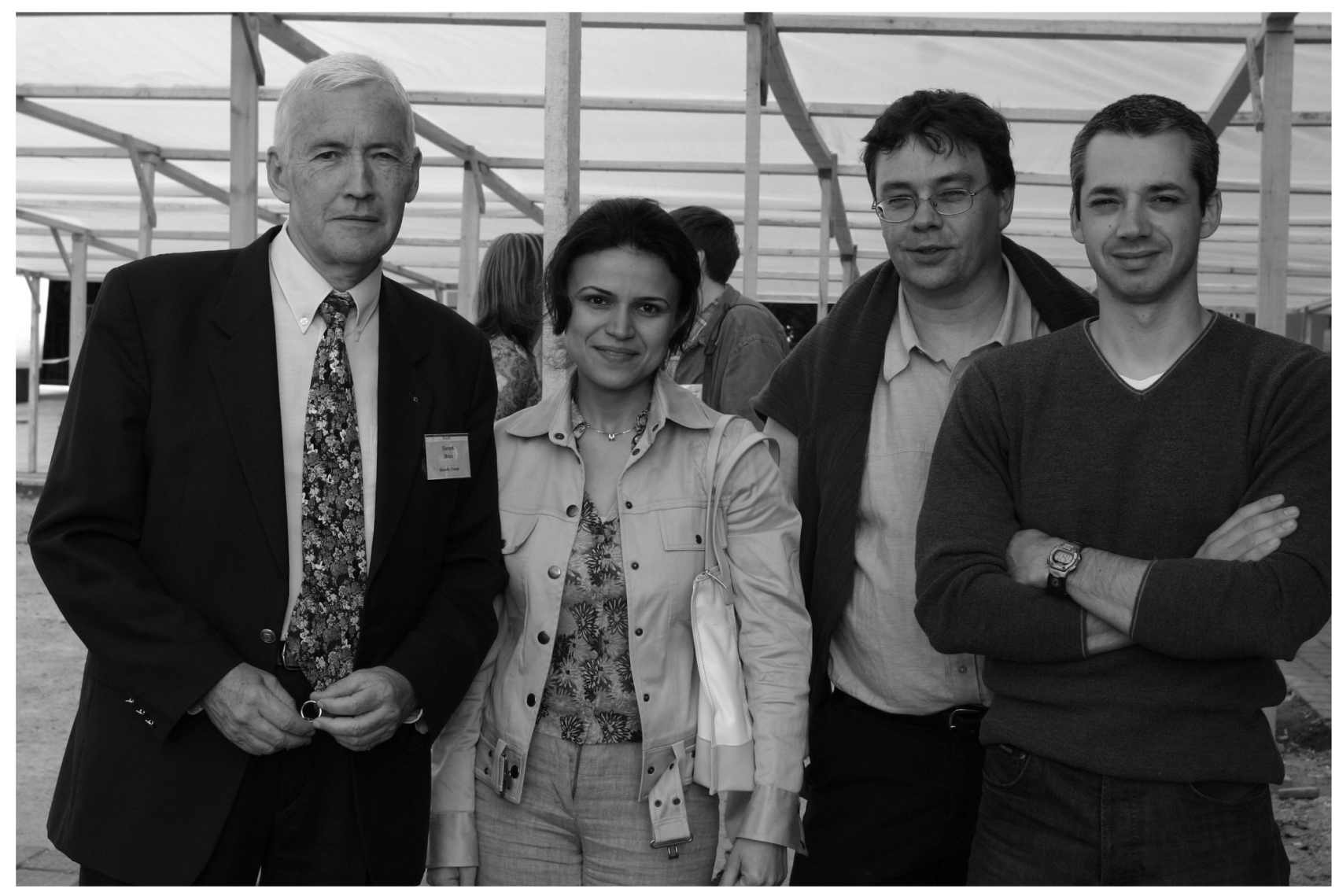

Prof. G. Moya, Dr. N. Chaabane, Prof. D. Mangelinck, Dr. A. Portavoce

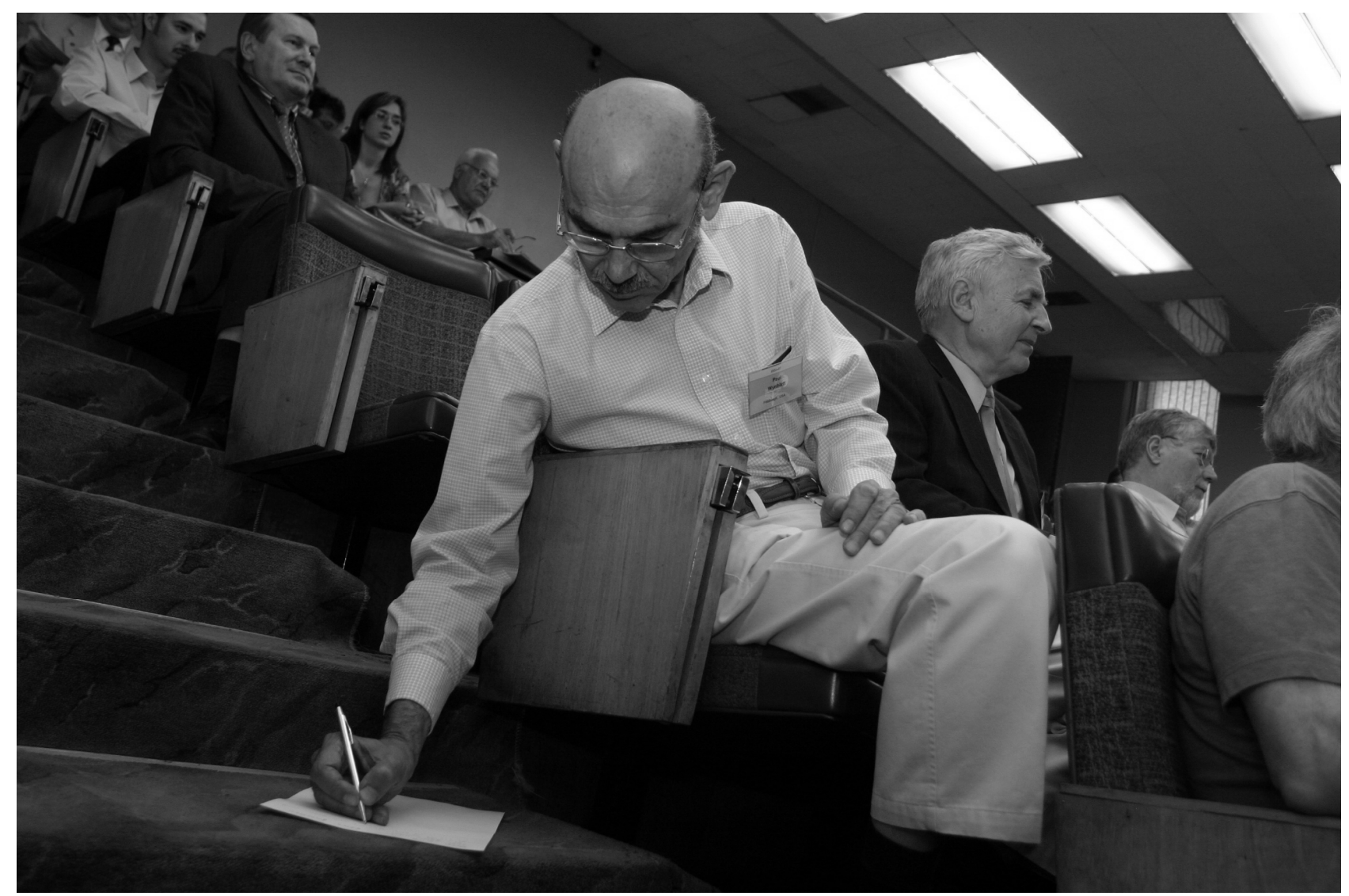

Prof. P. Wynblatt 